\title{
Analyzing Educational Testing Service Graduate Major Field Test Results
}

Barry Thornton, Ed.D., Jacksonville University, USA

Gordon Arbogast, Ph.D., Jacksonville University, USA

\begin{abstract}
The Educational Testing Service (ETS) created the Graduate Major Field Test in Business (GMFT-B) for MBA students. This test is administered to all MBA classes at Jacksonville University for the purpose of measuring student academic achievement and growth, as well as to assess educational outcomes. The test is given in the capstone course, Business Strategy and Policy, typically taken by students at the end of their MBA program. It provides valuable feedback to each student as to their standing with regard to students across the nation. A total of six years of data (2006 to 2011) was collected for analysis of these test scores. For the first half of this time period, Jacksonville University was in candidacy for accreditation by the Association for the Advancement of Colleges and Schools of Business (AACSB), and for the time period 2009-2011 it was an AACSB accredited institution. Executive MBA, evening MBA (also known as flex MBA) and day-time (accelerated) MBA classes took the exam over that time period. It was determined that the executive MBA student grades were significantly better than their counterparts in the evening (flex) and day-time (accelerated) MBA students at Jacksonville University. It was also found that there was no significant difference in student performance during the first half (AACSB candidacy) and second half (AACSB accreditation) of the time period under investigation.
\end{abstract}

Keywords: Assessment; Educational Testing Service; Graduate Major Field Test in Business; Executive MBA

\section{INTRODUCTION}

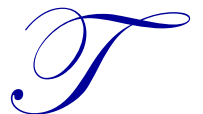

he Educational Testing Service (ETS) in Princeton New Jersey administers a number of major field tests in a variety of academic disciplines. These are at the undergraduate and graduate areas and cover some of the following subjects: Biology, Business Administration, Computer Science, Economics, and Psychology. The purpose of the tests is to measure student academic achievement and growth and to assess the educational outcomes of various major programs. Development of the Major Field Tests (MFTs) began in 1989 and was modeled on the development of the Graduate Record Examinations (GRE) subject tests. Unlike the GRE, the MFTs do not serve as a predictor of graduate school success, but are designed to measure the basic knowledge and understanding achieved by MBA students (Educational testing Service, 2006).

Experienced faculty members representing all of the relevant areas of a discipline determine the test specifications, questions and types of scores reported. The test assesses mastery of concepts, principles and knowledge by graduating Business students. In addition to factual knowledge, the test evaluates student's ability to analyze and solve problems, understand relationships and interpret material. ETS assessment experts subject each question to rigorous tests of validity and reliability. To ensure fairness and content relevance, the test is revised approximately every five years. A Comparative Data Guide is published each year containing tables of scaled scores and percentiles for individual student scores, departmental mean scores and subscores or group assessment indicators that the test supports. Nearly 1500 colleges and universities employ one or more of the MFTs each year (Educational Testing Service Major Field Tests, 2011). According to ETS, the Major Field Test in Business (MFT-B) provides institutions with information to use in curriculum evaluation, departmental self-study, and end-of-major outcomes assessment (ETS Handbook 2007). For example, Ursuline College used the MFT-B in such areas as psychology to identify program and curriculum changes that might enhance students' performances and help them to become better prepared applicants in the graduate school process (Frazier and Edmonds 2002). 


\section{ETS MAJOR FIELD TESTS IN BUSINESS}

Business schools are increasingly being required to locate sources of direct measurements that confirm and ensure student learning. Pressures are being exerted by such accreditation bodies as the Association for the Advancement of Collegiate Schools of Business (AACSB) International, regional university accrediting organizations such as the Southern Association of Colleges and Schools (SACS),and stakeholders such as lawmakers, students, alumni, faculty, administration, and community leaders. These stakeholders are increasingly demanding confirmation that business colleges demonstrate value to their students by producing knowledgeable and skilled graduates. Colleges and universities are now required to show that they are gathering data to demonstrate that their programs are being successful in this mission. This is often referred to in AACSB parlance as "closing the loop" (Wilson, 2008).

AACSB implemented new accreditation standards in 2003 that required business schools to assess student learning using new methods. An excellent source of direct information that confirms discipline specific learning that was readily available was the MFT-B. While the MFT-B is an excellent instrument, administrators and faculty are sometimes mystified how to review and interpret the test results. Little has been written about the success (or failure) arising from the use of standardized tests for outcomes assessment, and there is no prescribed process for moving from viewing results to improving academic programs and few examples were in the literature (Mirchandani, Lynch, and Hamilton 2001). However, over one-third of AACSB schools surveyed shortly thereafter reported that they were using the MFT to assess programs (Pringle \& Michel, 2007).

The MFT-B is specifically designed to assess mastery of concepts and principles as well as knowledge expected of students at the conclusion of a major in specific subject areas (ETS On-line Webinar 2007). Knowledge areas include Accounting, Economics, Management, Quantitative Business Analysis, Finance, Marketing, Legal and Social Environment, Information Systems, and International Issues. MFT-B questions are constructed and reviewed by committees of experts in each subject area. The test goes beyond measurement of factual knowledge. It also evaluates a students' ability to analyze and solve problems, understand relationships, and interpret material (ETS Handbook 2007). The MFT-B provides college and departmental administrators with important quantitative direct measurements of student learning to assess the effectiveness of their programs. Standardized test scores provide external validity and allow an institution to establish a baseline and benchmark against national norms (Mirchandani, Lynch, and Hamilton 2001). However, there are some cautions. Bycio and Allen (2007) recommend that great care be taken in interpreting the MFT-B scores. The meaning of the score is difficult to interpret without knowing such things as the extent of student motivation taking the test. The information is provided via a number of tables that at times can be difficult to assess objectively. ETS importantly notes that the data should be considered comparative rather than normative. The institutions employing the MFT-B do not proportionally represent the various types of higher education institutions (ETS Handbook 2007). Nonetheless the MFT-B provides one of the few tools available to compare student learning across the nation.

\section{ETS GRADUATE MAJOR FIELD TESTS IN BUSINESS}

The Graduate Management Field Test in Business Administration (GMFT-B) was developed to provide the same information as the MFT-B at the graduate (MBA) level. This test has the same basic format as the MFT-B and is administered in a similar fashion. It contains one hundred and twenty multiple choice questions. This test is completed over a three hour period (two sittings of sixty questions over an hour and a half each). The subject areas are as follows: Marketing, Management (includes Organizational Behavior, Human Resources Management, Strategic Management and Operations Planning/Management Science), Finance and Managerial Accounting. Each major area is weighted roughly $25 \%$ of the entire exam (ETS, 2005).

The GMFT-B was administered at Jacksonville University starting in 2006. The test is taken in the capstone course, Business Strategy and Policy, taken at the end of the MBA program. The test provides valuable feedback to each student as to their standing with regard to students across the nation. A total of six years of data has been collected for analysis over the period 2006-2011. Executive MBA, Evening MBA and a day-time (Accelerated) MBA classes took the exam over that time period. 
The GMFT-B has proved to be very useful at Jacksonville University. As the scores go from a maximum of 300 to a low of 220, MBA students have been able to determine how well they performed vis-à-vis their peers at other institutions around the country. In addition, all students are provided valuable feedback on how well they do in each of the major areas such as finance, accounting, management, and marketing. The national average for the test is 248.9. A student scoring a 270 knows that they are more than one standard deviation above the mean and are in the top $15 \%$ in the nation. The high grade that has been achieved by one of the JU Executive MBA students has been a 292 which put that student in the top $99.5 \%$ of the nation. Conversely students scoring in the 235 range are in the bottom $20 \%$ of the nation.

In addition to providing useful individual feedback, the GMFT-B provides valuable cumulative statistics for the DCOB. This data was provided to the AACSB accreditation team that visited in the fall of 2009. The DCOB was able to demonstrate that the mean scores of each class were above the national average and that several of its scores were one standard deviation above the national average. However, with data available from 2006 until 2011 it is felt that more useful information could be gleaned from this information.

\section{PROBLEM STATEMENTS}

With this in mind two major questions presented themselves for analysis. The first was whether or not the different types of MBA classes were performing differently on the exam. The formats of the MBA that are offered by the DCOB include the Executive MBA, Evening MBA and Accelerated (day time) MBA. As the accelerated MBA students are recruited in a very similar fashion to the evening students and take the same curriculum, it was felt that there were essentially two different formats, the Executive MBA and the traditional MBA. Thus the first problem statement was whether either one of these two formats were producing superior results. Secondly, there were major changes initiated in the DCOB in the 2008-2009 time periods to prepare for the AACSB initial accreditation visit in the late fall of 2009. Thus, the data breaks nicely into two pieces with the 2006-2008 data being pre-AACSB and the 2009-2011 data being the post-AACSB period. Could this data show a change due to the major structural changes in the DCOB driven by the desire to achieve AACSB status? Thus, the second problem statement concerned whether or not the changes in the DCOB made to achieve AACSB status had been reflected in improvement in student scores.

\section{HYPOTHESIS}

Null Hypothesis \#1: There is no relationship between the type of MBA (executive and traditional) and the score on the GMFT-B.

Alternate Hypothesis \#2: There is a relationship between the type of MBA (executive and traditional) and the score on the GMFT-B.

Null Hypothesis \#2: There is no relationship between the time period (pre-AACSB or post-AACSB) and the score on the GMFT-B.

Alternate Hypothesis \#2: There is a relationship between the time period (pre-AACSB or post-AACSB) and the score on the GMFT-B.

These hypotheses were tested at the five percent level of significance.

\section{DATA}

The GMFT-B is administered for assessment purposes in the strategic management class of both the traditional and executive MBA programs. This sample was selected from the period of time starting in the fall semester of 2006 and ending with the summer semester of 2011. The only semester during this time period when the test was not administered was the summer of 2010. During this time span, 435 MBA students took the test. Of these 435 students, 366 are traditional MBA and 69 are executive MBA. The number of scores from the preAACSB time period is 189 , while the number of scores from the post-AACSB time frame is 245 . The overall results of the ETS graduate business test are summarized in table 1, as well as the results by type of MBA and time period. 
Table 1: Descriptive Statistics for ETS Graduate Business Exam

\begin{tabular}{|l|c|c|c|c|c|}
\hline \multicolumn{1}{|c|}{ Group } & Sample Size & Mean & Std. Dev. & Maximum & Minimum \\
\hline All MBA & 435 & 255.7 & 14.0 & 292 & 220 \\
\hline Traditional Only & 366 & 254.4 & 13.7 & 288 & 220 \\
\hline Executive Only & 69 & 262.5 & 13.7 & 292 & 235 \\
\hline Pre-AACSB & 189 & 255.5 & 14.5 & 292 & 220 \\
\hline Post-AACSB & 246 & 255.9 & 13.6 & 288 & 225 \\
\hline
\end{tabular}

\section{METHODOLOGY}

A multiple regression model was constructed to examine the impact of type of MBA program (executive or traditional) and time period (pre-AACSB or post-AACSB) on GMFT-B scores. The dependent variable of the model is GMFT-B scores. The first independent variable is a binary variable for type of MBA program. This variable is set equal to one if the student who took the test was a member of the executive MBA program. It is set equal to zero if the student was enrolled in the traditional MBA program. The second independent variable is also a binary variable. It is set equal to zero for tests taken during the pre-AACSB time period, and one for those taken in the post-AACSB time period.

\section{RESULTS}

Table 2 shows the multiple regression results. While the model has significant explanatory power $(\mathrm{F}=$ 10.04 with an associated p-value of 0.000 ), it only explains $4 \%$ of the variation in GMFT-B scores. The null hypothesis that GMFT-B scores are not related to the type of program is strongly rejected. The sample evidence indicates that students enrolled in the executive MBA program can be expected to score 8.06 points higher than students enrolled in the traditional program. The null hypothesis that GMFT-B scores are not related to the time period when the exam was administered cannot be rejected. The p-value that corresponds to the test statistic for the estimated coefficient for this independent variable is much greater than the stated level of significance of five percent. The sample data suggests that there is no difference in GMFT-B scores in the pre-AACSB and postAACSB time periods.

Table 2: Multiple Regression Results

\begin{tabular}{|l|c|c|c|}
\hline \multicolumn{1}{|c|}{ Variable } & Estimated Coefficient & Test Statistic & P-Value \\
\hline Constant & 254.40 & $\mathrm{t}=248.1$ & 0.000 \\
\hline Type of Program & 8.06 & $\mathrm{t}=4.5$ & 0.000 \\
\hline Time Period & 0.03 & $\mathrm{t}=0.02$ & 0.983 \\
\hline Adjusted $\mathrm{R}^{2}=4.0 \%$ & $\mathrm{~F}=10.04$ & P-Value $=0.000$ \\
\hline
\end{tabular}

The differences in the distribution of exam scores by type of MBA and time period are also illustrated by the boxplots in Figures 1and 2.

\section{CONCLUSIONS}

The significant difference in the performance of EMBA students and normal MBA students is clearly evident in the analysis. This begs the question "Why do EMBAs perform better than traditional MBA students". Both receive the same MBA graduate degree and both take similar courses. There would appear to be three major differences in the two programs. The first is in the selection process. EMBA students are hand-picked by their respective employer organizations. As the cost is higher $(\$ 50,000$ vice approximately $\$ 25,000)$, companies are very discriminating and send only their best, high achievers and high potential managers and executives. Secondly, the program functions differently. The EMBA is a lock-step eighteen month program where students meet every two weeks on Fridays and Saturdays. The courses are ordered in an optimal sequence with the necessary reviews in statistics, accounting, finance and economics built into the beginning of the program. The traditional MBA is done in a very flexible fashion. Students take the core requirements in the order that they prefer and may take up to five years to complete the program. The lapse in time between materials presented in the front of the program until it is tested by the MFT-B could be as much as five years (or more if the student gets an exception to the five year requirement). 


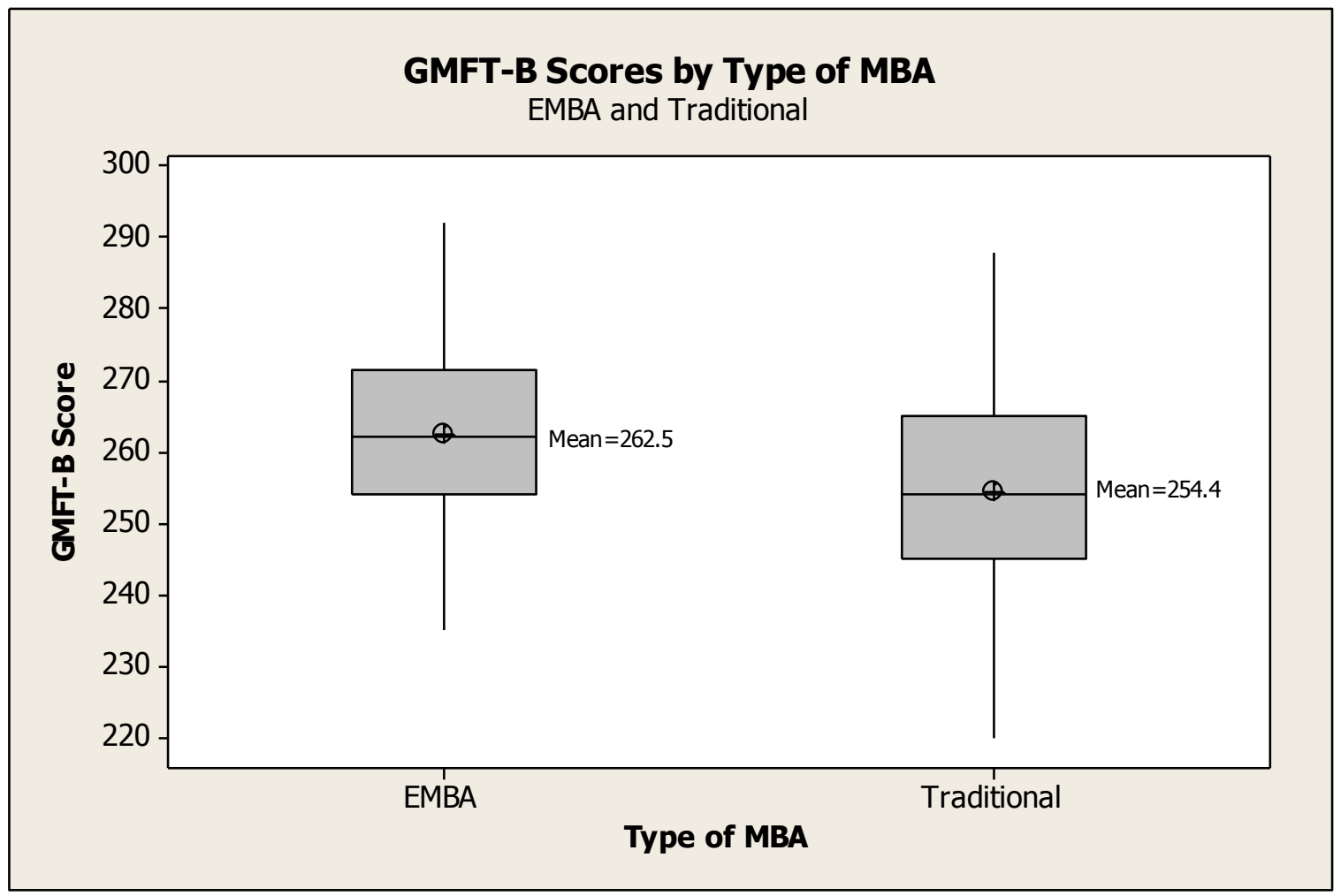

Figure 1: Boxplot for ETS Scores by MBA Type

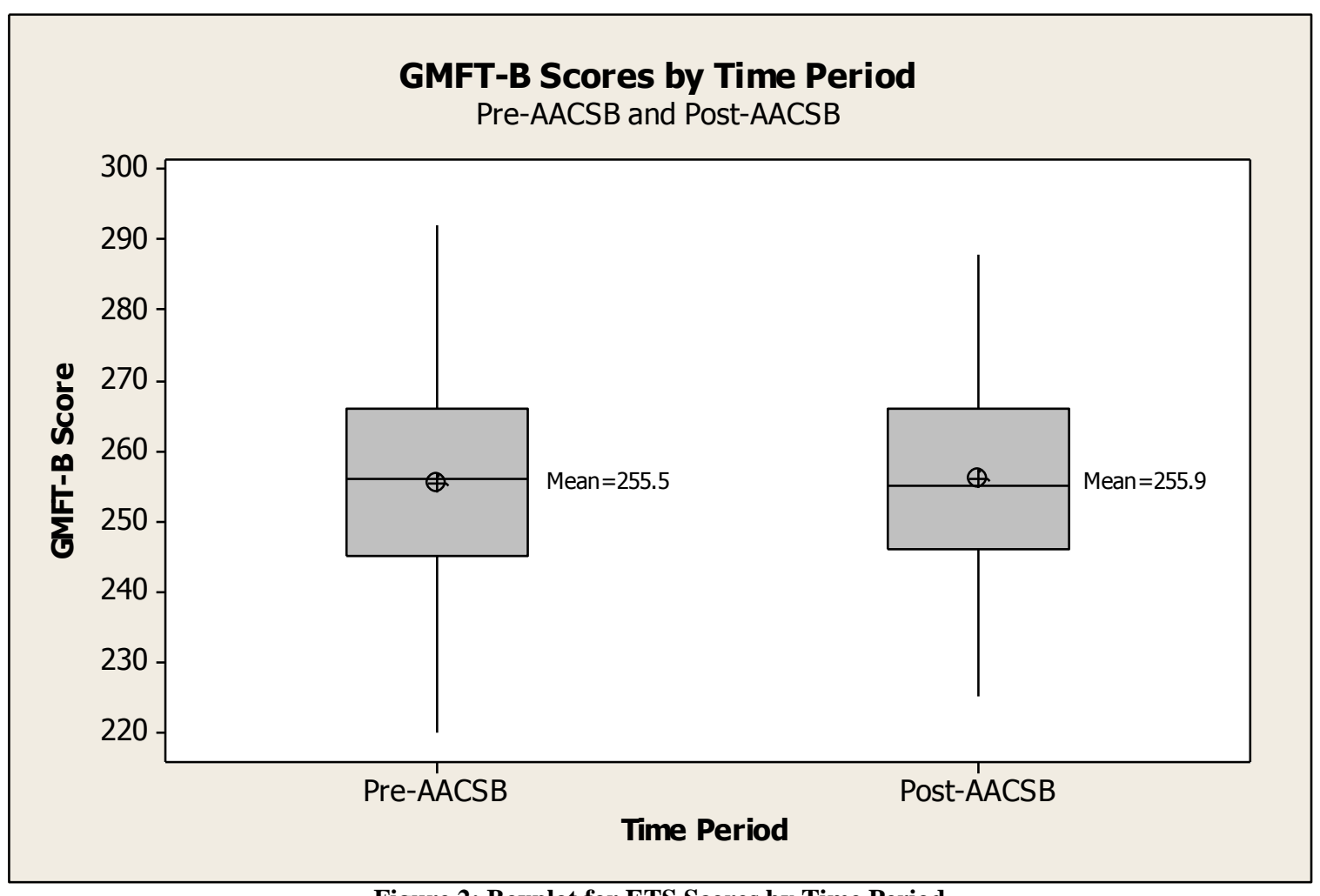

Figure 2: Boxplot for ETS Scores by Time Period 
The last difference is in the cohort nature of the EMBA program. Students are placed in a four or five person group that is carefully constructed to contain as many of the necessary business skills as is possible i.e. operations, marketing, information technology, finance, accounting etc. It is not uncommon to find a CFO or a CEO in the various groups. Thus, there is much business knowledge self-contained in each of the cohorts. EMBA students often comment in their out-processing briefs that they learned a great deal of business knowledge from the actual members in each of the cohorts.

The second major part of this analysis pertains to the performance of students in the pre- and post-AACSB classes. The JU Business College (Davis College of Business) received its accreditation in early 2010. Most of the processes were put in place in the 2008-2009 time-frames. Thus, by treating the scores in the 2006-2008 timeframe as pre-AACSB and the 2009-2011 scores as post-AACSB it was possible to evaluate if there was any difference between the two. It was concluded that there was no discernible difference between the two sets of scores. Thus, AACSB accreditation did not appear to have any significant effect on the performance of the various MBA classes at Jacksonville University.

The results discussed above are important to the JU Davis College of Business. For instance, employers who are discussing which MBA program to send their students to at JU often ask why they should spend twice as much money for the EMBA program. The results above allow a rational and empirical basis for advising why the EMBA program provides superior results.

\section{RECOMMENDATIONS}

Since the Accelerated MBA program was launched in 2011, it has provided very little data in which to study how effective the program is compared with the other two MBA options. A follow-on study needs to be conducted when sufficient data is available from the Accelerated MBA classes.

Another area that can be explored in a follow-on study is the variation in the scores in the individual subject areas that make up the GMFT-B test. The test provides results in each of the major areas of business, i.e. accounting, finance, marketing, management etc. This study only considered the overall score on the GMFT-B. It would be very interesting to see if the various major areas each contribute equally to the difference in scores between the EMBA and the MBA.

Lastly, it would be useful to compare the results between the graduate ETS scores and the undergraduate ETS scores. Although the tests are different, each ETS test has the same goal, i.e. to assess the level of performance of the students in essentially the same business areas. Where discrepancies exist between the two programs could shed light on potentially effective teaching and delivery styles of pedagogy.

\section{AUTHOR INFORMATION}

Dr. Barry Thornton is chair of the Economics Department at Jacksonville University. He earned a B.A. in economics from the University of Hartford in 1981. He then attended Florida State University on a College of Social Sciences Fellowship and received his M.S. in Economics in 1985. Dr. Thornton completed his doctorate in educational leadership from the University of North Florida in 2000. His research interests include the pricing of initial public offerings, the valuation of firms, and various topics in higher education. E-mail: bthornt@ju.edu (Corresponding author)

Dr. Gordon Arbogast is Department Chair of DSIM and Management and Professor of Management at Jacksonville University. His educational background includes Executive Education - Harvard University (1992), Ph.D. - Clemson University (1986); M.S.E.E. and M.S.I.M. Georgia Institute of Technology; and B.S. - U.S. Military Academy (1963). His academic experience includes Associate Dean and Director of Graduate Programs, 2005-2010; Chair, Department of Management, Decision Sciences and Information Technology; Professor of Management (Tenured), Jacksonville University, 1994-present; Permanent Associate Professor and Head, Department of Engineering, U.S. Military Academy, 1986-1989, Adjunct Professor of Management, Universities of Virginia and Maryland 1979-1983, and Assistant Professor of Electrical Engineering, Department of Elect. Engineering, U.S. Military Academy, 1970-1973. E-mail: garboga@ju.edu 


\section{REFERENCES}

1. Allen, J.S., \& Bycio, P. (1997).An Evaluation of the Educational Testing Service Major Field Achievement Test in Business. Journal of Accounting Education, 15, 503-514.

2. Bycio, P. \& Allen J.S. (2007). Factors Associated With Performance on the Educational Testing Service (ETS) Major Field Achievement Test in Business (MFAT-B). Journal of Education for Business, April/May, 196-201.

3. Educational Testing Service (2005).Master of Business Administration (4BMF), Higher Education Assessment, Princeton, New Jersey.

4. Educational Testing Service (2006). Major Field Tests. Princeton, NJ: Educational Testing Service.

5. Educational Testing Service (2006).Major Field Tests, Higher Education Assessment, Princeton, New Jersey.

6. Educational Testing Service (2007). Major Field Test: Comparative Data Guide. Princeton, NJ: Educational Testing Service.

7. Educational Testing Service (2007).A Guided Tour of the Major Field Tests Online Assessments. http://www.ets.org/Media/Tests/MFT/demo/mftdemo_hi.html

8. Educational Testing Service On-line Webinar (2007). Measuring the Performance of Specific Academic Programs. http://www.ets.org/Media/Tests/MFT/webinarVideo/MFT_ppt.swf. .

9. Educational testing Service (2011), ETS Major Field Tests, Higher Education Assessment, Princeton, New Jersey.

10. Frazier, T.W. \& Edmonds, C.L. (2002).Curriculum Predictors of Performance on the Major Field Test in Psychology II. Journal of Instructional Psychology, 29(1), 29-32

11. Mirchandani, D., Lynch, R., \& Hamilton, D. (2001).Using the ETS Major Field Test in Business: Implications for Assessment. Journal of Education for Business, 77(1), 51-55.

12. Stoloff, M. L. \& Feeney, K.J. (2002). The Major Field Test as an Assessment Tool for an Undergraduate psychology

13. Wilson, Phillip (2008). A Protocol for Analyzing the Major Field Test Results. Journal of Business and Behavioral Sciences, Vol. 19, No. 2, 33-45. 
NOTES 